\title{
Influence of Coloured LED Lights on the Occurrence of Fusarium Wilt in Pigeonpea
}

\author{
Snehal M. Bansod*, S.B. Sakhare, A.G. Deshmukh and M.P. Moharil \\ Biotechnology Centre, Dr. Panjabrao Deshmukh Krishi Vidyapeeth, Akola (M.S.), India \\ *Corresponding author
}

\begin{tabular}{|c|c|}
\hline \multicolumn{2}{|r|}{ A B S T R A C T } \\
\hline Keywords & \multirow{4}{*}{$\begin{array}{l}\text { The present investigation was conducted in green house to study the effect } \\
\text { of different coloured LEDs (Red, green, White, Blue and UV light) on the } \\
\text { subsequent occurrence of Fusarium wilt in Pigeonpea seedlings whose the } \\
\text { seeds were treated with different coloured lights prior to sowing. The seeds } \\
\text { treated with red LEDs for } 12 \text { and } 24 \text { hrs and blue light for } 24 \text { hrs prior to } \\
\text { sowing reduced the Fusarium wilt by upto } 71 \text { percent over control. The } \\
\text { disease incidence was recorded after } 45 \text { days of inoculation with Fusarium } \\
\text { udum culture was } 14.58 \text { per cent in Asha and } 46.94 \text { per cent in TAT-10 } \\
\text { respectively. }\end{array}$} \\
\hline $\begin{array}{l}\text { Light emitting } \\
\text { diodes, Pigeonpea, } \\
\text { Fusarium wilt, } \\
\text { Asha, Tat-10. }\end{array}$ & \\
\hline Article Info & \\
\hline $\begin{array}{l}\text { Accepted: } \\
\text { 15 October } 2017 \\
\text { Available Online: } \\
10 \text { December } 2017\end{array}$ & \\
\hline
\end{tabular}

\section{Introduction}

Pigeonpea production is greatly constrained by numerous biotic and abiotic stresses. The major biotic stresses affecting legumes are fungal diseases although insects, nematodes, viruses, bacteria and parasitic weeds can also drastically decrease pigeonpea production. Wilt caused by Fusarium udam Butler is the major constrain to pigeonpea production worldwide (Kannaiyan et al., 1984). The incidence of disease has been reported from 30 to 60 per cent at flowering and crop maturity stages (Kannaiyan and Nene, 1981), however it can cause yield losses up to 100 per cent in susceptible cultivars. In nature plants are exposed to light of different wavelengths from ultraviolet to far-red regions. Light of certain wavelengths (290$320 \mathrm{~nm}$ ) may affect certain host-pathogen interactions (Honda, 2000; Kumagai, 1988). Induction of plant defence against pathogen attack is regulated by a complex network of different signals. Interaction between Fusarium udum and host plants was found to enhance defence responses against wilt disease in resistant cultivars of pigeonpea. Light was reported as one of the important factors affecting disease development by inactivating toxins of pathogens in certain plant-pathogen interactions (Kohmoto et al., 1989). The development of light-emitting diodes (LEDs) in the last few decades has introduced growers to a new source of lighting that provides many superior advantages. LEDs represent an innovative artificial lighting source for plants both as supplemental or sole-source lighting, not only 
owing to their intensity, spectral and energy advances but also via the possibilities for targeted manipulation of metabolic responses in order to optimize plant productivity and quality. Plants have light receptors that detect visible light and generate a response. There are certain photoreceptors which get activated at specific wavelength of light. LED light is one of the sources which produce a constant source of light with specific wavelength. The hypothesis of this study is whether the wilt tolerance of pigeonpea seedlings could be improved with a light treatment.

\section{Materials and Methods}

\section{Seed material}

In this experiment, seed of two genotypes viz. Asha and TAT-10 were treated with fungicide solution for 5 minutes. Then washed with tap water for several times and were soaked in distilled water for 24 hours. Seeds were counted out in specific quantities (15 seeds for each treatment) and placed in standard sized (20 cm diameter) glass petri dishes lined with two layers of Whatman's filter paper. Filter papers were moistened with distilled water and seeds were randomly dispersed over the triangles formed by partitions in Petridishes by thin layer of cardboard. The petri dishes containing seeds were then placed in box, $15 \mathrm{~cm}$ wide at the top $22 \mathrm{~cm}$ at the bottom with a distance of $25 \mathrm{~cm}$ from bottom to top internally covered with the appropriate plastic filter according to color. One LED light with specific colour was fitted at the top of each box which was $20 \mathrm{~cm}$ above the level of the petri dish. After 12, 24 and 36 hrs seeds were sown in pots.

\section{Light treatment}

For irradiation different coloured Light Emitting Diodes (LEDs) such as Red, Green, White, Blue and UV light were used. Light intensities for the various colored were measured by a Digital Lux Light Meter (LX101, Lutron). The intensities of different coloured LEDs are given in Table 1.

\section{Fungus inoculation}

Seven days after sowing, the seedlings were inoculated with spore suspension culture of F. udum. The culture of Fungus Fusarium udum which affects the pigeon pea plant by causing Fusarium wilt disease was obtained from the Microbial Type Culture Collection and Gene Bank (MTCC) Chandigarh. The Fusarium udum culture was maintained on Potato Dextrose Agar (PDA) plates with timely subculturing.

This culture was used for infection to the seedlings grown in plastic pots. Seedlings with no pathogen infection (un-inoculated plants) treated as control. The pathogenicity assays were conducted in triplicates. In one replication 5 plants were grown. Two discs of $F$. udum about five $\mathrm{mm}$ diameter were cut, and suspended in $20 \mathrm{ml}$ distilled water and was shaken thoroughly to get good and uniform spore suspension. One drop of this spore suspension was placed on a haemocytometer and numbers of spores in 5 squares of haemocytometer at random were counted. The number of spores per $\mathrm{ml}$ was calculated with haemocytometer, using the formula given by Pathak (1984).

No. of spores per $\mathrm{ml}=\frac{\mathrm{N} \text { x } 1000}{\mathrm{X}}$

Where,

$\mathrm{N}=$ Total no. of spores counted/ no. of squares

$\mathrm{X}=$ Volume of mounting solution between the cover glass and above the squares counted 
After irradiation with different coloured LEDs the seeds were sown in pots and diseases incidence was recorded after 45 days. Per cent Disease incidence (PDI) was calculated by using formula given by Anjaneyareddy and Saifulla, (2005)

$$
\text { PDI = } \frac{\text { Number of plants wilted }}{\text {-------------------- x } 100}
$$

\section{Statistical Analysis}

Statistical analysis for data was carried out in a FCRD (Factorial Completely Randomized Design). The analysis of sixteen treatments for assessing the different coloured lights effect on two pigeonpea genotypes was done taking $\mathrm{V}_{1}$ and $\mathrm{V}_{2}$ as main treatments and $\mathrm{T}_{1}$ to $\mathrm{T}_{16}$ as sub treatments. The level of statistical significance to the experimental data was carried out as per procedure described by Gomez and Gomez (1984).

\section{Results and Discussion}

\section{Effect of genotypes}

Genotype Asha showed less wilt incidence as compared to susceptible genotype TAT-10 (Table 2). The disease incidence was 14.58 per cent in Asha whereas 46.94 per cent plants of TAT-10 were infected after 45 days of inoculation with Fusarium udum culture.

\section{Effect of light treatments}

Data regarding the effect of different coloured LEDs on wilt incidence is recorded in Table 2. From this data, it is observed that in red LEDs for 12 and $24 \mathrm{hrs}$ and blue LEDs for 24 hrs, only 14.4 per cent plants infected with wilt and blue light for $36 \mathrm{hrs}$ were found at par with the superior treatment red LEDs for $24 \mathrm{hrs}$. This decrease was 71 per cent over control and may be due to the red light irradiation that induces the production of antifungal substance(s) in plants.

Similar results were reported by various scientists while working on different plants. Certain wavelengths could be used to eliminate or maximize the abilities of fungi to proliferate or insects to navigate to host species (Mass et al., 2008). Irradiation with red light induced the accumulation of an antifungal substance in leaf tissue of broad bean leaves. This substance prohibited germination of spores of several fungal pathogens including soil borne fungi as reported by Islam et al., (1999). Islam and babadoost (2002) reported that the application of red light treatment induced disease resistance against Phytophthora capsici in pumpkin, pepper and tomato seedlings. Irradiation of Nicotiana benthamiana especially with blue and red wavelengths of light induced resistance against wildfire disease (Ahn et al., 2013).

\section{Genotype $x$ light interaction effects}

The data in respect of disease incidence is given in Table 2 and graphically represented in Figures 1. Treatment of red LEDs for 12 hrs and blue LEDs for $24 \mathrm{hrs}$ showed significant reduction in the occurrence of Fusarium wilt in Asha (4.4\%) followed by red $24 \mathrm{hrs}$ and blue LEDs for $36 \mathrm{hrs}(6.6 \%)$.

In Asha, red light treatment decrease disease incidence by 78 per cent over the control (20 $\%)$. The disease incidence percentage of TAT-10 genotype is presented in Table 2 and depicted in Figure 1. Red LEDs for $24 \mathrm{hrs}$ treatment reduced the percentage of wilt in TAT-10. In this treatment 20 per cent plants were infected with wilt. Whereas in control in which the seeds were not irradiated with any light source 82.2 per cent plants showed wilt infection. This decrease in percentage in red LEDs treatment was 72 per cent over control. 
Table.1 Details of light emitting diodes used to illuminating seeds

\begin{tabular}{|c|c|c|c|c|}
\hline $\begin{array}{l}\text { Sr. } \\
\text { No. }\end{array}$ & $\begin{array}{c}\text { Light Emitting } \\
\text { Diodes }\end{array}$ & $\begin{array}{c}\text { Intensity of Light } \\
\left(\mu \mathrm{mol} \mathrm{m}-\mathrm{s}^{-1}\right)\end{array}$ & $\begin{array}{c}\text { Wavelength } \\
\text { (nm) }\end{array}$ & Time duration \\
\hline 1 & Ultraviolet Light & 2.5 & $10-380$ & 5,10 and $20 \mathrm{mins}$ \\
\hline 2 & Blue LEDs & 5 & $450-495$ & 12,24 and $36 \mathrm{hrs}$ \\
\hline 3 & Green LEDs & 80 & $495-570$ & 12,24 and $36 \mathrm{hrs}$ \\
\hline 4 & Red LEDs & 25 & $620-750$ & 12,24 and $36 \mathrm{hrs}$ \\
\hline 5 & White LEDs & 25 & - & 12,24 and $36 \mathrm{hrs}$ \\
\hline
\end{tabular}

Table.2 Effect of different coloured LEDs on incidence of Fusarium wilt

\begin{tabular}{|c|c|c|}
\hline \multicolumn{2}{|c|}{ Genotypes } & Disease Incidence (\%) \\
\hline Asha & V1 & $14.58(21.08)$ \\
\hline TAT-10 & $\mathrm{V} 2$ & $46.94(43.44)$ \\
\hline \multicolumn{2}{|l|}{ S. E. $(\mathrm{m}) \pm$} & 0.62 \\
\hline C. D. at $5 \%$ & & 1.75 \\
\hline \multicolumn{3}{|c|}{ Light treatments } \\
\hline Control & T1 & 51.11(45.75) \\
\hline UV $5 \mathrm{~min}$ & $\mathrm{~T} 2$ & $50.0(45.48)$ \\
\hline UV $10 \mathrm{~min}$ & $\mathrm{~T} 3$ & $42.0(39.83)$ \\
\hline UV $15 \mathrm{~min}$ & $\mathrm{~T} 4$ & $41.1(38.97)$ \\
\hline Red 12 hrs & $\mathrm{T} 5$ & $14.4(21.64)$ \\
\hline Red $24 \mathrm{hrs}$ & T6 & $14.4(19.50)$ \\
\hline Red 36 hrs & $\mathrm{T} 7$ & 21.1(21.74) \\
\hline Green $12 \mathrm{hrs}$ & $\mathrm{T} 8$ & $30(32.78)$ \\
\hline Green $24 \mathrm{hrs}$ & T9 & $28.8(31.39)$ \\
\hline Green 36 hrs & T10 & $26.8(30.09)$ \\
\hline White $12 \mathrm{hrs}$ & T11 & $42.2(39.94)$ \\
\hline White $24 \mathrm{hrs}$ & T12 & $38.8(38.00)$ \\
\hline White $36 \mathrm{hrs}$ & T13 & $35.5(36.22)$ \\
\hline Blue $12 \mathrm{hrs}$ & T14 & $23.3(28.82)$ \\
\hline Blue $24 \mathrm{hrs}$ & T15 & $14.4(22.34)$ \\
\hline Blue 36 hrs & T16 & $17.7(23.72)$ \\
\hline \multicolumn{2}{|l|}{ S. E. $(\mathrm{m}) \pm$} & 1.76 \\
\hline \multicolumn{2}{|l|}{ C. D. at $5 \%$} & 4.96 \\
\hline Control (Asha) & V1T1 & $20.0(26.36)$ \\
\hline UV 5 min & V1T2 & $17.78(24.85)$ \\
\hline UV $10 \mathrm{~min}$ & V1T3 & $17.78(24.85)$ \\
\hline UV $15 \mathrm{~min}$ & V1T4 & $15.56(23.13)$ \\
\hline Red $12 \mathrm{hrs}$ & V1T5 & $4.4(13.70)$ \\
\hline Red $24 \mathrm{hrs}$ & V1T6 & $6.6(12.43)$ \\
\hline Red 36 hrs & V1T7 & $22.2(17.11)$ \\
\hline Green $12 \mathrm{hrs}$ & V1T8 & $20.0(26.36)$ \\
\hline Green $24 \mathrm{hrs}$ & V1T9 & $13.3(20.98)$ \\
\hline
\end{tabular}




\begin{tabular}{|l|l|c|}
\hline Green 36 hrs & V1T10 & $13.3(20.98)$ \\
\hline White 12 hrs & V1T11 & $20.0(26.36)$ \\
\hline White 24 hrs & V1T12 & $20.0(26.36)$ \\
\hline White 36 hrs & V1T13 & $22.2(28.07)$ \\
\hline Blue 12 hrs & V1T14 & $8.89(17.11)$ \\
\hline Blue 24 hrs & V1T15 & $4.44(13.70)$ \\
\hline Blue 36 hrs & V1T16 & $6.67(14.96)$ \\
\hline Control (TAT-10) & V2T1 & $82.2(65.15)$ \\
\hline UV 5 min & V2T2 & $82.2(66.12)$ \\
\hline UV 10 min & V2T3 & $66.67(54.80)$ \\
\hline UV 15 min & V2T4 & $66.67(54.80)$ \\
\hline Red 12 hrs & V2T5 & $24.4(29.58)$ \\
\hline Red 24 hrs & V2T6 & $20.0(26.36)$ \\
\hline Red 36 hrs & V2T7 & $22.2(27.57)$ \\
\hline Green 12 hrs & V2T8 & $40.0(39.19)$ \\
\hline Green 24 hrs & V2T9 & $44.4(41.80)$ \\
\hline Green 36 hrs & V2T10 & $40.0(39.19)$ \\
\hline White 12 hrs & V2T11 & $64.4(53.52)$ \\
\hline White 24 hrs & V2T12 & $57.7(49.64)$ \\
\hline White 36 hrs & V2T13 & $48.4(44.36)$ \\
\hline Blue 12 hrs & V2T14 & $37.7(40.52)$ \\
\hline Blue 24 hrs & V2T15 & $24.4(30.97)$ \\
\hline Blue 36 hrs & V2T16 & $28.8(32.48)$ \\
\hline S. E. (m) \pm & & 2.48 \\
\hline C. D. at 5\% & & 7.02 \\
\hline
\end{tabular}

Fig.1 Effect of different coloured LEDs on incidence of Fusarium wilt

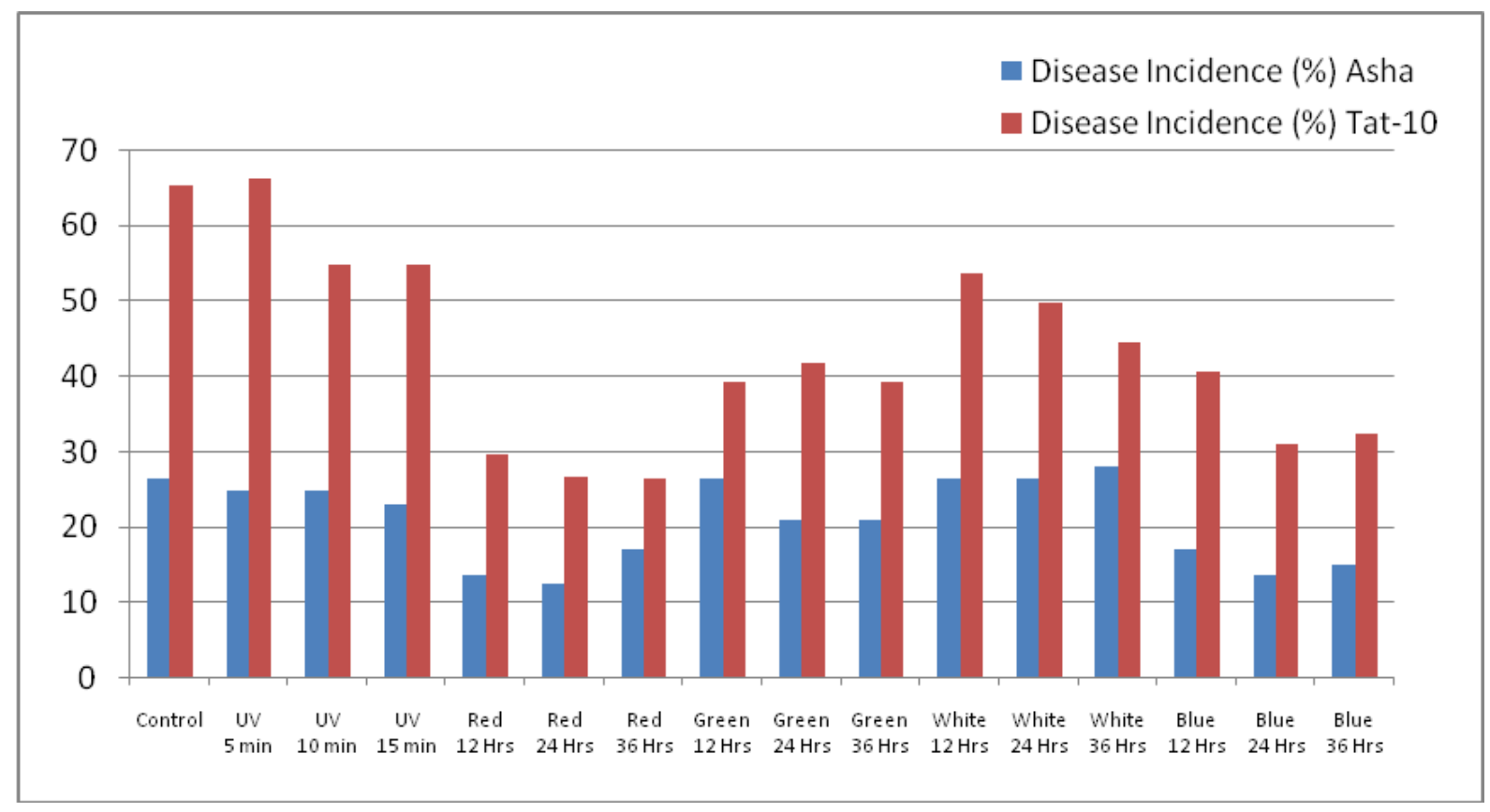


Furthermore, Wang et al., (2010) found that disease resistance to Sphaerotheca fuliginea in cucumber plants was induced by red light. Red light was also reported to suppress the lesion development of $P$. capsici on detached leaves of eggplant, pepper, pumpkin, and watermelon (Umezu et al., 1999). Induced resistance in plants by red light against Alternaria tennuissima has also been reported by Rahman et al., (2001). Khanam et al., (2005) reported that enhanced catalase activity under red light treatment contributes to the inhibition of lesion formation and fungal development on broad bean leaves infected with Botrytis cinerea. Kim et al., (2013) suggested that Blue LEDs suppresses the development of gray mold of $B$. Cinerea in tomato via enhanced accumulation of proline and antioxidative response. Thus numerous studies have suggested that physiological resistance of plants to environmental stresses including pathogen attack is closely connected with specific light treatments.

In conclusion, current study suggests that red and blue LEDs are highly efficient to protect crop plants from fungal attacks. This may be due to the increased production of osmoprotectants and antioxidants, including ROS scavenging enzymes.

\section{References}

Ahn, S.Y., S. Kim, K.H. Baek and H. Yun, 2013. Inhibiting wildfire and inducing defense-related gene expression by LED treatment on Nicotiana benthamiana. J. Plant Pathol. 95: 477-483.

Anjaneyareddy, B. and M. Saifulla, 2005. Evaluation of Promising Pigeonpea Genotypes and Host Differentials Against Fusarium udum Butler. Karnataka J. Agric. Sci., 18(3): 691693.

Gomez K A and A A Gomez (1984).
Statistical procedure for Agriculture Research. A Wiley- Interscience publication. John. Wiley and sons. New Yark.

Honda, Y., 2000. UV-B radiation decreases resistance and red light enhances it in certain combination of plant and pathogen, p. 21-23. Proc. COE-IGE Intl. Symp.: Plant and ultraviolet-B radiation-Effects of increasing ultraviolet-B radiation on ecosystem and resistance of plant to ultraviolet-B radiation. Tohoku Univ., Japan.

Islam, S.Z. and M. Babadoost, 2002. Effect of Red Light Treatment of Seedlings of Pepper, Pumpkin, and Tomato on the Occurrence of Phytophthora Damping off. Hort. Science. 37(4): 678-681.

Islam, S.Z., Y. Honda and S. Arase. 1999. Some characteristics of red lightinduced substance(s) against Botrytis cinerea produced in broadbean leaflets. J. Phytopathol. 147: 65-70.

Kannaiyan J. and Y. L. Nene, 1981. Influence of wilt at different growth stages on yield loss in Pigeonpea. Trop. Pest Manage. 27: 141.

Kannaiyan, J., Y.L. Nene, M.V. Reddy, J.G. Ryan and T.N. Raju, 1984. Prevalence of pigeonpea disease and associated crop losses in Asia Africa and America. Trop. Pest Manage 30: 62-71.

Khanam, N.N., M. Ueno, J. Kihara, Y.M. Honda and S. Arase, 2005. Suppression of red light-induced resistance in broad beans to Botrytis cinerea by salicylic acid. Physiol. Mol. Plant, 66: 20-29.

Kim, K., H.S. Kook, Y.J. Jang, W.H. Lee, S.K. Kannan, J.C. Chae and K.J. Lee, 2013. The Effect of Blue-light-emitting Diodes on Antioxidant Properties and Resistance to Botrytis cinerea in Tomato. J Plant Pathol Microb. 4:9. http://dx.doi.org/10.4172/2157-7471.10 00203.

Kohmoto, K., H. Otani, M. Kodama and S. 
Nishimura, 1989. Host recognition: Can accessibility to fungal invasion be induced by host specific toxins without necessitating necrotic cell death, pp 249-265.

Kumagai, T., 1988. Photocontrol of fungal development. Photochem. Photobiol. 47: 889-896.

Massa, G.D., H.H. Kim, R.M. Wheeler and C.A. Mitchell, 2008. Plant productivity in response to LED to lighting. Hort. Science. 43: 1951-1956.

Pathak, V.N., 1984. Laboratory Manual of Plant Pathology. Second edition. Oxford and IBH Publishing Co. Pvt. Ltd. New Delhi, 11-12.

Rahman, M.Z., N. Muroguchi, S. Arase and
Y. Honda, 2001. Effect of red light on the development of leaf spot disease in broadbean caused by Alternaria tenuissima. Proc. Annu. Mtg. Phytopathol. Soc. of Japan, Sendai.

Umezu, H., S.Z. Islam and Y. Honda, 1999. Red lightinduced resistance in some plants. Bul. Assoc. Plant Protect. Shimane Pref., Japan 24:55-57.

Wang, H., Y.P. Jiang, H.J. Yu, X.J. Xia and K. Shi, 2010. Light quality affects incidence of powdery mildew expression of defence-related genes and associated metabolism in cucumber plants. Eur. J. Plant Pathol. 127: 125135.

\section{How to cite this article:}

Snehal M. Bansod, S.B. Sakhare, A.G. Deshmukh and Moharil, M.P. 2017. Influence of Coloured LED Lights on the Occurrence of Fusarium Wilt in Pigeonpea. Int.J.Curr.Microbiol.App.Sci. 6(12): 2017-2023. doi: https://doi.org/10.20546/ijcmas.2017.612.232 